\title{
THE SUMMER MEETING IN STATE COLLEGE
}

The forty-third Summer Meeting of the Society and the twentieth Colloquium were held at The Pennsylvania State College, State College, Pennsylvania, from Tuesday to Friday, September 7-10, 1937. The Mathematical Association of America met Monday afternoon and Tuesday morning. About four hundred seventy-five persons attended the meetings, among whom were the following two hundred seventy-four members of the Society:

C. R. Adams, R. B. Adams, V. W. Adkisson, R. P. Agnew, L. V. Ahlfors, H. W. Alexander, E. B. Allen, V. A. Ames, R. L. Anderson, R. C. Archibald, H. T. R. Aude, Frank Ayres, W. L. Ayres, C. L. Bacon, H. M. Bacon, Reinhold Baer, I. A. Barnett, E. R. Beckwith, Garrett Birkhoff, G. D. Birkhoff, A. H. Black, H. L. Black, H. F. Blichfeldt, G. A. Bliss, Henry Blumberg, R. P. Boas, H. R. Brahana, C. C. Bramble, F. L. Brooks, E. T. Browne, J. A. Bullard, F. J. H. Burkett, J. H. Bushey, J. Hughes Bushey, W. H. Bussey, W. D. Cairns, J. W. Calkin, C. C. Camp, W. B. Campbell, Leonard Carlitz, I. S. Carroll, E. W. Chittenden, R. V. Churchill, A. B. Coble, Teresa Cohen, J. B. Coleman, L. P. Copeland, Byron Cosby, Richard Courant, H. S. M. Coxeter, H. B. Curry, D. R. Curtiss, J. H. Curtiss, E. H. Cutler, Tobias Dantzig, P. H. Daus, H. A. Davis, H. T. Davis, J. E. Davis, F. F. Decker, L. L. Dines, C. H. Dix, J. L. Doob, H. L. Dorwart, R. H. Downing, Arnold Dresden, D. M. Dribin, J. A. Eiesland, O. J. Farrell, E. J. Finan, M. M. Flood, W. B. Ford, Tomlinson Fort, R. M. Foster, J. S. Frame, Bernard Friedman, Kurt Friedrichs, A. H. Frink, Orrin Frink, T. C. Fry, A. S. Gale, B. P. Gill, R. E. Gilman, J. W. Givens, W. O. Gordon, W. C. Graustein, T. E. Gravatt, C. H. Graves, W. L. Graves, M. B. Greenebaum, J. A. Greenwood, F. L. Griffin, V. G. Grove, Margaret Gurney, B. L. Hagen, Israel Halperin, J. A. Hamilton, E. H. Hanson, W. L. Hart, M. L. Hartung, Alan Hazeltine, G. A. Hedlund, E. R. Hedrick, Coleman Herpel, H. C. Hicks, E. H. C. Hildebrandt, T. H. Hildebrandt, T. R. Hollcroft, Charles Hopkins, W. A. Hurwitz, W. L. Hutchings, M. H. Ingraham, Dunham Jackson, Nathan Jacobson, R. L. Jeffrey, F. A. Jeffries, Fritz John, Evan Johnson, R. A. Johnson, R. F. Johnson, B. W. Jones, H. S. Kaltenborn, A. J. Kempner, L. S. Kennison, G. S. Ketchum, P. W. Ketchum, S. C. Kleene, J. R. Kline, M. S. Knebelman, J. C. Knipp, H. L. Krall, C. C. Krieger, W. D. Lambert, K. W. Lamson, O. E. Lancaster, A. E. Landry, E. P. Lane, R. E. Langer, C. G. Latimer, V V. Latshaw, Solomon Lefschetz, D. H. Lehmer, D. C. Lewis, F. P. Lewis, Marie Litzinger, T. R. Long, L. L. Lowenstein, R. G. Lubben, N. H. McCoy, W. H. McEwen, R. S. McKee, J. V. McKelvey, J. C. C. McKinsey, L. A. MacColl, C. C. MacDuffee, Saunders MacLane, H. F. MacNeish, A. J. Maria, W. T. Martin, A. E. Meder, W. I. Miller, U. G. Mitchell, E. B. Mode, Virginia Modesitt, E. C. Molina, E. I. Moody, C. N. Moore, R. L. Moore, C. B. Morrey, Richard 
Morris, A. P. Morse, H. M. Morse, David Moskovitz, E. J. Moulton, J. R. Musselman, John von Neumann, M. W. Newson, C. O. Oakley, R. E. O'Connor, E. G. Olds, F. W. Owens, H. B. Owens, J. C. Oxtoby, Gordon Pall, H. A. Perkins, R. M. Peters, T. S. Peterson, A. E. Pitcher, H. A. Rademacher, O. J. Ramler, W. C. Randels, J. F. Randolph, Robert Rawhouser, M. S. Rees, C. N. Reynolds, C. E. Rhodes, Moses Richardson, R. G. D. Richardson, D. E. Richmond, H. L. Rietz, J. F. Ritt, H. P. Robertson, G. de B. Robinson, L. B. Robinson, S. L. Robinson, J. B. Rosenbach, C. A. Rupp, N. E. Rutt, A. C. Schaeffer, I. J. Schoenberg, G. E. Schweigert, C. H. W. Sedgewick, R. W. Sedgewick, Wladimir Seidel, I. M. Sheffer, L. W. Sheridan, Max Shiffman, J. A. Shohat, C. G. Shover, R. G. Simond, M. E. Sinclair, James Singer, E. R. Sleight, C. S. Slichter, M. M. Slotnick, L. L. Smail, C. E. Smith, W. M. Smith, Virgil Snyder, G. W. Starcher, O. H. Stecker, N. E. Steenrod, M. H. Stone, M. M. Sullivan, J. L. Synge, Gabriel Szegö, J. D. Tamarkin, A. H. Taub, A. E. Taylor, J. S. Taylor, M. E. Taylor, T. Y. Thomas, C. C. Torrance, W. J. Trjitzinsky, A. W. Tucker, Annita Tuller, B. M. Turner, J. L. Vanderslice, H. S. Vandiver, I. L. Van Dyck, H. E. Vaughan, M. E. G. Waddell, C. C. Wagner, R. W. Wagner, R. J. Walker, J. L. Walsh, R. M. Walter, S. E. Warschawski, Warren Weaver, M. S. Webster, J. V. Wehausen, A. P. Wheeler, A. L. Whiteman, E. A. Whitman, Hassler Whitney, Norbert Wiener, L. R. Wilcox, K. P. Williams, E. W. Wilson, F. E. Wood, F. L. Wren, F. M. Wright, Oscar Zariski, Leo Zippin.

The Colloquium Lectures on the subject Continuous geometry were delivered by Professor John von Neumann of The Institute for Advanced Study on Tuesday afternoon and Wednesday, Thursday, and Friday mornings. The presiding officers at the four lectures were, in order, President R. L. Moore, Vice-President Norbert Wiener, Dean G. D. Birkhoff, and Professor M. H. Stone. The attendance was one hundred sixty-nine. These lectures will be published as a volume of the Colloquium Publications.

On Thursday afternoon, by invitation of the Program Committee, Professor Hassler Whitney of Harvard University gave an address entitled Topological properties of differentiable manifolds. This address will appear in an early issue of the Bulletin.

President R. L. Moore presided at the business meeting and general session Thursday afternoon; Professor J. R. Kline at the general session Wednesday morning. The presiding officers at the sectional sessions were as follows: Analysis, Professors R. P. Agnew, L. V. Ahlfors, and W. J. Trjitzinsky; Algebra, Mr. Garrett Birkhoff and Professor Gordon Pall; Topology, President R. L. Moore; Geometry, Professor Oscar Zariski.

Headquarters for the meetings were in the lobby of Old Main. 
The dormitories of the College were available, at a reasonable charge, to the members of both organizations and their guests.

Arrangements for the entertainment of those attending the meetings were excellent. They began Monday morning with a conducted tour in the neighboring mountains. On Monday evening, a musical recital by Mrs. C. C. Wagner, Professor Teresa Cohen, and Professor T. C. Benton was given at the Nittany Lion Inn. Tea was served in Old Main by the ladies of the local Department of Mathematics on Monday and Tuesday afternoons.

A reception was held Tuesday evening in Old Main at which President Ralph D. Hetzel of The Pennsylvania State College and Mrs. Hetzel greeted the mathematicians and their guests.

On Wednesday, a special luncheon for women, sponsored by the local chapter of Sigma Delta Epsilon, was held in honor of the women who were pioneers in mathematical research in America. The guests of honor were Professor Mary Winston Newson (Ph.D., Göttingen, 1897), the first American woman to receive the $\mathrm{Ph} . \mathrm{D}$. degree in mathematics at a German university, and Professors Clara E. Smith and Clara L. Bacon. The attendance was sixty-seven. Wednesday afternoon was devoted to a picnic excursion to Nature Study Camp, Seven Mountains.

On Thursday morning, there was a textile exhibit and a lecture, Science in the home, by Dr. Pauline Mack, Professor of Textile Chemistry at The Pennsylvania State College. On Thursday afternoon, Professor and Mrs. F. W. Owens entertained at their home.

A joint dinner for the members of the Society and the Association was held Thursday evening at the Nittany Lion Inn. Professor Virgil Snyder was toastmaster. The first speaker, Dean H. P. Hammond of The Pennsylvania State College, welcomed the mathematicians to State College. The other speakers were Professor R. L. Moore, President of the Society, Professor A. J. Kempner, President of the Association, and Dr. T. C. Fry, Executive Secretary of the Committee on the Semicentennial of the Society. Professor W. L. Hart presented a joint resolution on behalf of the members of both mathematical organizations thanking the President, officers, and members of the Department of Mathematics of The Pennsylvania State College 
for their competent arrangements and cordial hospitality. The attendance at the dinner was three hundred eleven.

The Council met on Tuesday, September 7, at 1:00 p.m., again on Wednesday, September 8, at 8:00 p.m., and finally at 10:00 p.m. on September 9, all the sessions being in Old Main, Pennsylvania State College.

The Secretary announced the election of the following persons to membership in the Society:

Mr. Howard Wright Alexander, Lehigh University;

Dr. Philip Osborne Bell, University of Kansas;

Mr. Lafayette Boyd Hedge, Brown University;

Professor Ralph Ernest Huston, Rensselaer Polytechnic Institute;

Professor Henri Albert Jordan, Georgetown University;

Dr. Otis Ewing Lancaster, University of Maryland;

Mr. William Spencer Litterick, The Peddie School, Hightstown, N. J.;

Miss Virginia Modesitt, University of Illinois;

Professor Parry Moon, Massachusetts Institute of Technology;

Mr. Charles W. Moran, Loyola University, Chicago, Ill.;

Mr. Haim Reingold, University of Cincinnati;

Mr. Eugene Kerfoot Ritter, University of Richmond;

Professor Ching-lai Shen, Soochow University, Soochow, China;

Mr. Seymour Sherman, Cornell University;

Professor Felix Perry Welch, Mississippi State College.

As nominees of the California Institute of Technology:

Mr. Hubert Andrew Arnold, California Institute of Technology;

Mr. Robert Palmer Dilworth, California Institute of Technology;

Mr. Newman Arnold Hall, California Institute of Technology;

Mr. Donald Holmes Hyers, California Institute of Technology;

Mr. Edwin Woolman Paxson, California Institute of Technology.

As nominees of Lehigh University:

Mr. Edward Stewart Kennedy, Lehigh University;

Mr. Donald Long Waidelich, Lehigh University.

As a nominee of the Metropolitan Life Insurance Company:

Mr. James A. Hamilton, Metropolitan Life Insurance Company, New York, N. Y.

As a nominee of the Department of Mathematics of Wayne University: Mr. Anthony Gerard Fleiger, Detroit Edison Company, Detroit, Mich.

It was announced that Dr. Isaac Opatowski, Royal Higher Institute of Engineering, Turin, Italy, had entered the Society under the reciprocity agreement with the Unione Matematica Italiana.

The following institution and department were elected to institutional membership in the Society:

Trinity College, Hartford, Conn.;

Department of Mathematics, Vassar College. 
The following appointments by President Moore were reported: as a member of the committee to consider the question of the Society's sponsorship of the William Lowell Putnam Competition to replace Professor J. D. Tamarkin, Professor C. G. Latimer (new chairman, Professor Virgil Snyder); as representative of the Society at the Semicentennial Celebration of the Founding of the University of Wyoming, Professor C. A. Hutchinson; as representative of the Society at the One Hundredth Anniversary of the Founding of Davidson College, Davidson, North Carolina, on June 6-8, Professor J. B. Coleman; as representative of the Society at the Third International American Conference to be held in Mexico City in August, 1937, Professor M. S. Vallarta; as a committee to consider the Society's connection with the American Documentation Institute, Dr. H. W. Tyler (chairman), Professors R. C. Archibald and R. L. Wilder.

Various announcements were made regarding the Semicentennial Celebration of the Founding of the American Mathematical Society, a notice of which appeared on page 593 of the September number of this Bulletin.

The 1938 meeting in Chicago is to be held on April 8-9. The place of the Annual Meeting of 1938 is to be Richmond and Williamsburg.

It was announced that the 1937 Gibbs Lecture is to be presented by Professor C. A. Kraus, his title being The present status of the theory of electrolytes.

Committees on the International Congress of Mathematicians to be held in Cambridge, Massachusetts, in 1940 were appointed as follows:

Organizing Committee: Professor W. C. Graustein (chairman), Dean G. D. Birkhoff, Professors G. A. Bliss, G. C. Evans, J. R. Kline, Solomon Lefschetz, and Oystein Ore, Dean R. G. D. Richardson, Professors M. H. Stone, J. L. Synge, J. D. Tamarkin, J. M. Thomas, and Norbert Wiener.

Editorial Committee: Professors Einar Hille (chairman), F. D. Murnaghan, and P. A. Smith.

Financial Committee: Professors Marston Morse (chairman), J. L. Coolidge, M. H. Ingraham, and H. B. Phillips. Secretary: Dean R. G. D. Richardson. 
Two committees on arrangements were appointed: for the Charlottesville Meeting, April 15-16, 1938, Professors G. T. Whyburn (chairman), J. J. Luck, and T. R. Hollcroft; for the Annual Meeting, 1938, Professors J. M. Stetson (chairman), E. J. McShane, G. A. Larew, T. R. Hollcroft, and C. H. Wheeler.

The Council recommended to the Society that the by-laws be amended so as to provide for a fourth Associate Secretary.

Professors A. A. Albert and M. H. Stone were invited to give Colloquium lectures at the Summer Meeting of 1939. A book by Professor C. N. Moore entitled Summable Series and Convergence Factors was accepted for the Colloquium Publications.

In view of the decision of the Mathematical Association of America to give the full right of way to the Society at the Semicentennial Celebration and not to hold a meeting itself, a cordial invitation was extended to its members to participate in all festivities.

A resolution regarding the work of Professor H. E. Slaught was adopted as follows:

The Council notes with deep regret the death of Herbert Ellsworth Slaught on May 21, 1937. An active member of the Society almost from its foundation, secretary of the Chicago Section of the Society from 1906 to 1916, and always an enthusiastic and intelligent promoter of mathematics, of mathematical education, and of the interests of mathematicians, he contributed uniquely to the development of mathematics in America. As a teacher and an editor he rendered unusual service, but probably his greatest contribution lay in his success in founding the Mathematical Association of America, devoted to the interests of collegiate mathematics. After the American Mathematical Society in 1915 voted to restrict its activities to the promotion of mathematical research, it was under Professor Slaught's inspiration and guidance that the Association was formed; and it was through his wise counsels that its policies were developed in such a manner that it has so effectively and so harmoniously supplemented the work of the Society. The Council of the Society takes this occasion to express its appreciation of the fine achievements of the Association, and of the uniformly friendly and effective cooperation which has obtained between the Society and the Association since the latter was founded. 
The titles and cross references to abstracts of papers read at this meeting are given below. Papers numbered 1 to 11 were presented Tuesday afternoon; papers 12 to 19 Wednesday morning; papers 20 to 40 Thursday morning; paper 41 Thursday afternoon; and papers 42 to 54 Friday morning. The remainder were read by title. Rev. W. C. Doyle was introduced by Professor Francis Regan, Mr. J. K. L. MacDonald by Professor W. A. Hurwitz, Mr. H. W. Alexander by Professor M. S. Knebelman, Mr. C. E. Springer by Professor E. D. Meacham, Mrs. E. M. Torrance by Professor J. D. Tamarkin, Dr. D. L. Netzorg by Professor W. J. Trjitzinsky, Mr. Philip Hall by Mr. Garrett Birkhoff, Mr. V. G. Iyer and Professor O. E. Glenn by Professor T. R. Hollcroft, Mr. J. K. Senior by Professor A. C. Lunn. Paper number 21 was presented by Dr. G. S. Ketchum, 31 by Mr. G. R. Kraus, 33 by Professor M. S. Knebelman, and 44 by Dr. J. F. Randolph. Papers whose abstract numbers are followed by the letter $t$ were read by title.

1. Self-adjoint differential operators of elliptic type. Resolvent kernels, by Dr. J. W. Calkin. (Abstract 43-9-323.)

2. A further generalization of Lambert series, by Rev. W. C. Doyle. (Abstract 43-5-268-t.)

3. On the definition of differential operators, by Dr. Kurt Friedrichs. (Abstract 43-9-329.)

4. On the representation of bounded analytic functions by sequences of polynomials, by Professor O. J. Farrell. (Abstract 43-9-327.)

5. Bounds for parameters in n-noded solutions of Sturm-Liouville equations, by Mr. J. K. L. MacDonald. (Abstract 43-9-345.)

6. The measure of transitive geodesics on certain three-dimensional manifolds, by Miss Annita Tuller. (Abstract 43-7-284.)

7. Normal extensions of quartic fields with the symmetric group, by Dr. D. M. Dribin (National Research Fellow). (Abstract 43-9-326.)

8. An analog of the von Staudt-Clausen theorem, by Professor Leonard Carlitz. (Abstract 43-7-291.)

9. Applications of generalized quaternions to regularity of ternary quadratic forms (preliminary report), by Professor Gordon Pall. (Abstract 43-7-302.)

10. Groups with abelian central quotient group, by Professor Reinhold Baer. (Abstract 43-9-316.)

11. An application of Schläfli's modular equation to a conjec- 
ture of Ramanujan, by Professor D. H. Lehmer. (Abstract 43-7-299.)

12. p-algebras over a field generated by one indeterminate, by Professor A. A. Albert. (Abstract 43-7-287-t.)

13. On existence of linear functionals defined over linear spaces, by Professor R. P. Agnew. (Abstract 43-9-314.)

14. On certain equations in matrices whose elements belong to a division algebra, by Professor M. H. Ingraham. (Abstract 43-9-335.)

15. On continuous transformations of bounded variation in the plane, by Professor Tibor Radó. (Abstract 43-9-356-t.)

16. Orthogonal polynomials in two complex variables, by Professor Dunham Jackson. (Abstract 43-5-276.)

17. An extension of Schwarz's lemma, by Professor L. V. Ahlfors. (Abstract 43-5-265.)

18. Some properties of formal deducibility, by Professor H. B. Curry. (Abstract 43-9-325.)

19. The expansion theory of ordinary differential systems of the first order, by Professor R. E. Langer. (Abstract 43-9-340.)

20. A note on the Cesaro method of summation, by Dr. J. H. Curtiss. (Abstract 43-7-278.)

21. On a certain class of non-linear expansions of an arbitrary analytic function, by Dr. G. S. Ketchum and Dr. P. W. Ketchum. (Abstract 43-9-338.)

22. Some theorems related to number theory, by Professor J. J. Gergen. (Abstract 43-5-274-t.)

23. The calculus of variations applied to Nörlund's sum, by Professor Tomlinson Fort. (Abstract 43-7-295.)

24. Theory of non-linear singular differential systems, by Professor W. J. Trjitzinsky. (Abstract 43-9-364.)

25. Asymptotic relations for derivatives, by Dr. R. P. Boas, Jr. (National Research Fellow). (Abstract 43-7-289.)

26. Linear equations with an infinity of unknowns, by $\mathrm{Mr}$. L. L. Lowenstein. (Abstract 43-9-343.)

27. Displacement of equilibrium point of Green's function for an annulus, by Dr. A. J. Maria. (Abstract 43-9-346.)

28. Existence theorem for the flow of an ideal incompressible fluid in two dimensions, by Dr. A. C. Schaeffer. (Abstract 43-7-308.) 
29. The role of the mean curvature in the immersion theory of surfaces, by Mr. H. W. Alexander. (Abstract 43-9-315.)

30. On a canonical form of the system of differential equations defining a ruled surface, by Dr. W. L. Hutchings. (Abstract 43-9-333.)

31. A classification of rational plane cubic curves, by Mr. G. R. Kraus and Professor J. H. Neelley. (Abstract 43-7-277.)

32. Spin representation of inversions, by Dr. A. H. Taub. (Abstract 43-9-360.)

33. Parallel vector fields, by Professor M. S. Knebelman and Professor Walther Mayer. (Abstract 43-9-339.)

34. On the metric differential geometry of a general surface in a linear space of four dimensions, by Mr. C. E. Springer. (Abstract 43-7-311)

35. Plane peanian continua with unique maps on the sphere and in the plane, by Professor V. W. Adkisson. (Abstract 43-7286.)

36. Perfectly compact Hausdorff spaces in which a normal space may be embedded, by Professor R. G. Lubben. (Abstract 43-9-344.)

37. Degenerate cycles bound, by Professor A. W. Tucker. (Abstract 43-9-365.)

38. A note on topological fields, by Dr. Nathan Jacobson. (Abstract 43-9-336.)

39. On periodic transformations of complexes, by Dr. Moses Richardson. (Abstract 43-7-306.)

40. Bounded sets in topological linear spaces, by Mr. J. V. Wehausen. (Abstract 43-7-312.)

41. An extensive class of analytic functions, by Dean G. D. Birkhoff. (Abstract 43-9-366.)

42. Analyticity of equilibrium figures of rotation, by Dr. Bernard Friedman. (Abstract 43-7-296.)

43. Superposition on monotonic functions, by Mrs. E. M. Torrance. (Abstract 43-9-363.)

44. Gillespie linear measure for point sets, by Dr. A. P. Morse and Dr. J. F. Randolph. (Abstract 43-9-350.)

45. The solution of linear boundary value problems in physics by means of the Laplace transformation. II, by Professor R. V. Churchill. (Abstract 43-7-292.) 
46. On the solution of the differential equation $u_{x_{1} x_{1}}+u_{x_{2} x_{2}}$ $=u_{x_{8} x_{8}}+u_{x_{4} x_{4}}$, by Professor Fritz John. (Abstract 43-9-337.)

47. On dependent probabilities, by Mr. Garrett Birkhoff. (Abstract 43-9-321.)

48. On completely continuous linear transformations (preliminary report), by Mr. Ingo Maddaus, Jr. (Abstract 43-7-300-t.)

49. Certain inequalities for functions of exponential type belonging to $L$ along the real axis, by Dr. D. L. Netzorg. (Abstract 43-9-352.)

50. Representation of states in quantum mechanics by entire functions (preliminary report), by Dr. D. C. Lewis. (Abstract 43-9-342.)

51. Sets of conjugate matrices, by Professor E. T. Browne. (Abstract 43-9-322.)

52. The distribution of sums of squares of rank differences for the case of eight individuals, by Professor E. G. Olds. (Abstract 43-9-354.)

53. Variance of a general matching problem, by Dr. J. A. Greenwood. (Abstract 43-9-331.)

54. A graphical representation for the simple group of order 504, by Professor H. S. M. Coxeter. (Abstract 43-7-293.)

55. Extensions of linear functionals, with applications to limits, integrals, measures, and densities, by Professor R. P. Agnew and Dr. A. P. Morse. (Abstract 43-5-273-t.)

56. Abelian fields and duality of abelian groups, by Professor Reinhold Baer. (Abstract 43-7-288-t.)

57. Groups with preassigned central and central quotient group, by Professor Reinhold Baer. (Abstract 43-9-317-t.)

58. Halley's methods for the solution of equations, by Professor Harry Bateman. (Abstract 43-9-318-t.)

59. Remarks on the problem of Plateau, by Dr. E. F. Beckenbach. (Abstract 43-9-319-t.)

60. On a classification of integral functions by means of certain invariant point properties. A supplement, by Dr. M. T. Bird. (Abstract 43-5-266-t.)

61. Additive functions on Boolean algebras, by Mr. Garrett Birkhoff. (Abstract 43-9-320-t.)

62. Normal coordinates for extremals transversal to a manifold, by Professor S. S. Cairns. (Abstract 43-7-290-t.) 
63. Combinatory logic as a semigroup (preliminary report), by Professor Alonzo Church. (Abstract 43-5-267-t.)

64. On tensors relative to the extended point transformation, by Professor H. V. Craig. (Abstract 43-9-324-t.)

65. Conformal transformations and the subspaces of a Riemann space, by Dr. Aaron Fialkow. (Abstract 43-9-328-t.)

66. The Riemannian curvature of a hypersurface, by Dr. Aaron Fialkow. (Abstract 43-7-294-t.)

67. A multiplier rule in abstract spaces, by Dr. H. H. Goldstine. (Abstract 43-9-330-t.)

68. On primitive groups of linear substitutions, by Mr, Philip Hall. (Abstract 43-5-275-t.)

69. Fixed points under homeomorphisms of continua which are not connected im kleinen, by Mr. O. H. Hamilton. (Abstract 43-7281-t.)

70. On functional equations in linear topological spaces, by Dr. D. H. Hyers. (Abstract 43-9-334-t.)

71. Initial motion of a forced dissipative dynamical system under a sudden change in the force regime, by $\mathrm{Mr}$. W. H. Ingram. (Abstract 43-5-264-t.)

72. On effective sets of points in relation to integral functions. by Mr. V. G. Iyer. (Abstract 43-7-282-t.)

73. The geometry of conformal symmetry (Schwarzian reflexion) by Professor Edward Kasner. (Abstract 43-7-297-t.)

74. The two conformal invariants of fifth order, by Professor Edward Kasner. (Abstract 43-7-298-t.)

75. On the growth of analytic functions, by Dr. Norman Levinson. (Abstract 43-5-269-t.)

76. Invariant manifolds near an invariant point of unstable type, by Dr. D. C. Lewis. (Abstract 43-9-341-t.)

77. Subrings of direct sums, by Professor N. H. McCoy. (Abstract 43-7-283-t)

78. A note on an extension of Bernstein's theorem, by Professor W. H. McEwen. (Abstract 43-9-347-t.)

79. General conformal differential geometry, by Professor A. D. Michal. (Abstract 43-9-348-t.)

80. General projective differential geometry. by Professor A. D. Michal. (Abstract 43-9-349-t.)

81. An extension of Markoff's comparison theorems for zeros 
of orthogonal polynomials, by Dr. D. L. Netzorg. (Abstract 43-9-351-t.)

82. The mean number of solutions of $\phi(x)=n$, by Dr. D. L. Netzorg. (Abstract 43-9-353-t.)

83. The maximum of a superharmonic function, by Mr. Philip Newman. (Abstract 43 7-301-t.)

84. The quaternion congruence $\bar{t} a t \equiv b(\bmod g)$ and the equation $h(8 n+1)=x^{2}+y^{2}+z^{2}$, by Professor Gordon Pall. (Abstract 43-7-303-t.)

85. On symmetric determinants, by Professor W. V. Parker. (Abstract 43-7-304-t.)

86. The characteristic roots of a matrix, by Professor W. V. Parker. (Abstract 43-7-305-t.)

87. Existence theorems for solutions of differential equations of non-integral order, by Dr. A. E. Pitcher and Dr. W. E. Sewell. (Abstract 43-9-355-t.)

88. On certain points in the theory of algebraic differential equations, by Professor J. F. Ritt. (Abstract 43-9-357-t.)

89. A quasi-analytic function which satisfies a functional equation, by Mr. L. B. Robinson. (Abstract 43-9-358-t.)

90. The nth prime is greater than $n \log n$, by Dr. J. B. Rosser. (Abstract 43-7-307-t.)

91. On a classification of metrical relations in the foundations of geometry, by Dr. A. R. Schweitzer. (Abstract 43-7-309-t.)

92. A theory of congruence in the foundations of geometry, by Dr. A. R. Schweitzer. (Abstract 43-7-310-t.)

93. The derivative of a polynomial on various curves of the complex plane, by Dr. W. E. Sewell. (Abstract 43-7-279-t.)

94. Spin representations of groups of motion of Riemannian spaces of constant curvature, by Dr. A. H. Taub. (Abstract 43-9361-t.)

95. Ternary trilinear forms in the field of complex numbers, by Dr. R. M. Thrall and Dr. J. H. Chanler. (Abstract 43-9-362-t.)

96. The successive iterates of the Stieltjes kernel expressed in terms of the elementary functions, by Professor D. V. Widder. (Abstract 43-7-280-t.)

97. Decompositions of compact metric spaces, by Professor R. L. Wilder. (Abstract 43-5-270-t.) 
98. Neighborhoods in locally connected spaces, by Professor R. L. Wilder. (Abstract 43-5-272-t.)

99. Property $S_{n}$, by Professor R. L. Wilder. (Abstract 43-5271-t.)

100. The groups of order 64 (preliminary report), By $\mathrm{Mr}$. Philip Hall and Mr. J. K. Senior. (Abstract 43-9-332-t.)

101. The generalized law of Bode as a mathematical principle, by Professor O. E. Glenn. (Abstract 43-9-367-t.)

T. R. HollCrofT, Associate Secretary 